\title{
A INFLUÊNCIA CULTURAL NA FISIOLOGIA DO CORPO SEXUADO VINVULADO À HEGEMONIA MASCULINA NA DIVISÃO SEXUAL DO TRABALHO NA ARBITRAGEM EM FUTEBOL
}

\author{
Ineildes Calheiro dos $\operatorname{Santos}^{1}$ \\ Suely Aldir Messeder ${ }^{2}$
}

\section{RESUMO}

Com a temática das diferenças físicas entre os sexos e a problemática do androcentrismo na fisiologia do corpo sexuado, relativo à fragilidade versus força física sexualmente inata, utilizados como dispositivo de poder na divisão sexual do esporte, no futebol, embora que exista a presença maciça de homens arbitrando jogos, as mulheres vêm gradativamente ocupando este espaço profissional, mas, quando nos debruçamos no aparato institucional que regulamenta as normas para o campo de arbitragem, nota-se que existe fortemente um apelo ao dimorfismo sexual. Portanto, esse estudo, resultado de indagações concernentes à pesquisa de mestrado em desenvolvimento, cujo objeto, enfoca a participação das mulheres na arbitragem do futebol brasileiro, no âmbito do trabalho e nos limites do poder, tendo como liame, o sexo na ótica do desempenho físico, tem como objetivo discutir sobre a influência cultural nos comportamentos dos corpos sexuados, tentando perceber como a perspectiva feminista sobre tecnologia de gênero poderá favorecer na compreensão das histórias de vida das mulheres árbitras de futebol, que se submeteram aos testes físicos da seleção de arbitragem. A partir de um olhar feminista e pós-estruturalista, que busca desestabilização de paradigmas biológicos/naturais, partimos dos seguintes questionamentos: de que forma o processo cultural influencia nas diferenças físicas entre os sexos e na divisão sexual do trabalho desportivo? E como pensar na equidade social de gênero, a partir da igualdade física entre os sexos? Teórica e metodologicamente, foi realizada uma análise crítica focando teorias culturais, feministas e biológicas, onde refletimos sobre o corpo/sexo construído, comportamentos fisiológicos adquiridos e a divisão sexual no mercado futebolístico, conectados à tecnologia de gênero e ao poder. A priori, constatamos o androcentrismo e a resistência á abertura do campo para as mulheres, uma vez que estas atuam sob controle físico e á base de desigualdades no quantitativo estipulado para os sexos e nas oportunidades, ao mesmo tempo em que, nas normas para tornar-se árbitros (as) exige-se a igualdade física entre os sexos, comprovados na bateria de avaliações físicas, onde neste requisito, grande parte das mulheres é reprovada.

Palavras-chave: Tecnologia de Gênero. Poder. Arbitragem em Futebol. Divisão Sexual do Trabalho. Identidade. Natureza/Cultura.

${ }^{1}$ Mestranda em Crítica Cultural na Universidade do Estado da Bahia - UNEB. Licenciada e especialista em Educação Física. Membro do grupo de pesquisa "Enlace" da Universidade do Estado da Bahia - UNEB. Bolsista, financiada pela FAPESB. E-mail: ildafrica@yahoo.com.br.

${ }^{2}$ Doutora em Antropologia. Professora do Mestrado em Crítica Cultural e do Doutorado Multi-institucional e Multidisciplinar em Difusão do Conhecimento. Primeira secretária da ABEH - Associação Brasileira de Estudos da Homocultura. Coordenadora do Grupo de pesquisa Enlace/UNEB. E-mail: suelymesseder@gmail.com. 


\section{ABSTRACT}

\section{The cultural influence in body physiology the male hegemony in sexual division} of labor in soccer arbitration

With the theme of physical differences between sexes and the problem of androcentrism in the physiology of the sexual body, aiming at an innate fragility against sexually physical strength, used as power device in the sexual division of sport, in soccer, although there are the massive presence of men arbitrating these kind of games, women have gradually occupying this professional space, but when we look back at the institutional apparatus which regulates the standards for the field of arbitration, we note that there is an appeal strongly to sexual dimorphism. Therefore, this study, questions results concerning master's research on development, whose object focuses on women's participation in the arbitration of Brazilian soccer, the scope of work and the limits of power, with the bond, the gender perspective in physical performance, aims to discuss the cultural influence on the behavior of sexed bodies, trying to understand how the feminist perspective on gender technology can facilitate the understanding of the life stories of women soccer referees, who underwent testing physical tests of selection arbitration. From a feminist and poststructuralist gaze that seeks to destabilize biological/natural paradigms, we set the following questions: how the cultural process influences the physical differences between the sexes and the sexual division of labor sporty? And how to think of social gender equality, from the physical equality between gender? Theoretically and methodologically, a critical analysis focusing on cultural, biological and feminist theories, which reflect on the body/gender constructed, acquired physiological behaviors and the sexual division in the soccer market, connected to gender and power technology was performed. A priori, we found the androcentrism and the resistance to opening the field for women, since they operate under physical control and will be based inequalities within stipulated for the sexes quantitative and opportunities at the same time, the rules for making them referees, it required to physical gender equality, proven in all sequence of physical assessments, where on this requirement, most women is deprecated.

Keywords: Gender Technology. Power. Arbitration in Soccer. Labor Sexual Division. Identity. Nature/Culture. 


\section{Introdução}

Este estudo é resultado de indagações e inquisições concernentes à pesquisa de mestrado em fase de desenvolvimento, cujo projeto ${ }^{3}$ visa discutir, a partir do mundo do trabalho de arbitragem em futebol no Brasil, a questão da diferença do desempenho físico e esportivo entre homens e mulheres e a problemática da divisão sexual no trabalho desportivo.

Para se ter noção das distâncias sexuais ou disparidades no "trabalho" do futebol, vale lembrar que, nos últimos anos, vêm ocorrendo no país megaeventos futebolísticos como a Copa das Confederações e a Copa do Mundo, respectivamente em 2013 e 2014, e, para o futuro, as Olimpíadas, agendadas para o ano 2016. Mesmo com o desenvolvimento desses eventos, nota-se a persistência da ausência de mulheres na função de arbitragem.

Neste estudo, a arbitragem em futebol é um recorte que delimita um assunto amplo, embora não discutido com a mesma extensão na academia: o futebol empreendedor e que adentre as diferenças sociais e sexuais. Aqui, destaco a questão física, no dimorfismo, vista como empecilho para as inserções de gênero no trabalho desportivo, tendo sua base nas diferenças físicas, fundamentadas em paradigmas de fragilidade versus força inata nos corpos, isto é, no biológico/natural entre os sexos.

Na discussão, não trataremos somente das diferenças de sexo/gênero, mas suas correlações, como os conceitos, preconceitos, ações e realizações em decorrência das distinções e da tecnologia de gênero apresentadas nas leis, normas e regras sociais, sobretudo o poder. Discutiremos que, ao mesmo tempo em que ocorre o apego aos paradigmas correlacionados aos corpos sexuados, iniciando um "jogo" de perpetuação androcêntrica no campo do futebol, ocorre também um apelo à construção social dos corpos, adentrando no "jogo" as noções de "natureza cultura". E como na condição de gênero e no fator exclusão, tanto um como o outro são como caminhos que dão no mesmo lugar, como um labirinto?

\footnotetext{
${ }^{3}$ Intitulado, As mulheres no mundo da arbitragem futebolística: a construção dos corpos e a dominação masculina.
} 
No segundo momento, mostraremos que, com a chegada das mulheres nos esportes, temos exemplos que desestabilizam o fenômeno biológico/natural e uma nova identidade de gênero, com as mulheres fortes. Desta forma, entendemos que as discussões através de dimorfismos sexuais são pontos relevantes nos trâmites em relação às melhorias para as mulheres no mercado de trabalho desportivo. Assim sendo, partimos do questionamento: de que forma o processo cultural influencia nas diferenças físicas entre os sexos e na divisão sexual do trabalho desportivo? E como pensar na equidade social de gênero a partir da igualdade física entre os sexos? Teórica e metodologicamente, realizamos uma análise crítica focando teorias culturais, feministas e biológicas, na qual refletimos sobre o corpo/sexo construído, comportamentos fisiológicos adquiridos e a divisão sexual no mercado futebolístico, conectados à tecnologia de gênero.

Nosso objetivo é discutir sobre a influência cultural nos comportamentos dos corpos sexuados, tentando perceber como a perspectiva feminista sobre tecnologia de gênero poderá favorecer nas nossas compreensões.

\section{Cultura: como compreender?}

Tentando compreender o que é cultura, analisando alguns estudos, vimos que, em meados do século 20 , já havia olhares que distorciam a lógica naturalizante, embora, muitas vezes, esta não fosse interpretada de tal forma, como observado neste trecho: "[...] Nada de novo foi dito até agora, e definições semelhantes de cultura têm sido proferidas e aperfeiçoadas [...]" (MALINOWSKI, 1975, p. 42). Nesta obra, no texto intitulado "Uma teoria científica da cultura" (p, 47), o autor afirma que nenhuma invenção, revolução, mudança social ou intelectual ocorre sem terem sido criadas novas necessidades, sendo adaptadas ao processo ou a uma instituição cultural novas técnicas de conhecimentos ou de crenças. Notamos o que diz:

[...] não há atividade humana, combinada ou individual, que possamos considerar como puramente fisiológica, ou seja, "natural" ou não disciplinada. Mesmo atividades como respirar [...] Os processosfisiológicos dentro do corpo humano são afetados pela ventilação pela rotina [...] pelas condições de segurança [...] Há uma constante interação entre o organismo e 
o meio secundário em que ele existe, ou seja, a cultura. Em suma, os seres humanos vivem por normas, costumes, tradições e regras, que são resultado de uma interação [...] (p.70).

Como vimos, ao mesmo tempo em que o autor diz que não há nada de novo (no período de seus estudos), ele se contradiz, ao pontuar fenômenos vinculado à construção fisiológica no meio social, que nada mais é do que algo novo, uma vez que a lógica naturalizante coloca o processo fisiológico como essência da natureza. No trecho, a fisiologia do corpo ocorre na interação sociocultural, onde podemos interpretar que se as diferenças físicas corporais-fisiológicas existem, elas são humanas e não sexuais.

Ao fazermos uma analogia do estudo do autor supracitado com o de Adam Kuper, no texto intitulado "Cultura: a visão dos antropólogos" (2002), nota-se a expressão do surgimento de algo novo na cultura, quando revela que: "essa cultura humana comum evoluiu" (p,288).

A diferença entre ambos não estaria na forma discursiva?Onde o segundo autor (cujo texto original data-se de 1999),mostra ousadia na fala, pondo em evidencia a quebra dos padrões culturais com a ideia do progresso cultural, mas que a evolução da cultura humana, enquanto ideologia,já estava sendo desenvolvida com o anterior.

Na sequência, pensando a cultura como um fenômeno construído e a identidade vinculada, vejamos o que diz Kuper:

[...] cultura aqui é essencialmente uma questão de ideias e valores, uma atitude mental coletiva. As ideias, os valores, a cosmologia, a estética e os princípios morais são expressados por intermédio de símbolos e, portanto - se o meio é a mensagem - cultura podia ser descrita como um sistema simbólico. [...] (KUPER, 2002, p. 288).

O autor confirma a questão ao se reportar a outros antropólogos, como Terence Turner, trazendo o multiculturalismo no discurso, afirmando ser um movimento para mudança (Ibd., 2002, p.289-290). Herskovits (p. 304-305), para quem cultura é adquirida, vinculando a questão do poder como algo que se forma no processo, além de afirmar que a cultura confere identidade a uma pessoa e se valendo de Stuart Hall, assevera que "a cultura se forma" (p. 305).

Kuper, referindo-se a Eric Wolf, diz que a melhor forma de ver uma cultura é "como uma série de processos que constroem, reconstroem e 
desmantelam materiais culturais, em resposta a determinantes identificáveis" (p. 310). Desta maneira, o autor parece estar tanto desvendando conceitos e diversas faces da cultura, quanto tentando compreender a visão dos antropólogos. Por fím, ele afirma que "Todos nós temos identidades múltiplas, e mesmo que eu admita ter uma identidade cultural primária, pode ser que eu não queira me ajustar a ela [...]" (p.311).

Para nós, a cultura é múltipla e plural e se constitui em um conjunto de fatores que está sempre se compondo, juntamente com o progresso do mundo, ou se aproveitando das brechas do progresso deste e suas possibilidades para, então, se desmantelar e reconstruir, ou mesmo construir, uma nova identidade nesse ínterim. Portanto, mutável.

É nesse sentido que trazemos uma discussão baseada numa nova identidade que se desenha, concernente a corpo/sexo/gênero relacionados a fatores comportamentais, isto é, a práticas que correspondem às mulheres fisicamente fortes, que, com a evolução cultural, têm contribuído para dissolver tabus, quebrar regras naturalizantes e desestabilizar paradigmas. Desta forma, tentaremos compreender, na temática seguinte, a construção dos corpos na tecnologia de gênero e, em seguida, mergulharemos em uma abordagem que nos remete a refletir sobre uma nova identidade de gênero e novos campos esportivos, androcêntricos, de atuação feminina.

\section{De que forma o processo cultural influencia nas diferenças físicas entre os sexos e na divisão sexual do trabalho desportivo?}

Tentando responder à questão, refletindo sobre a relação entre o dimorfismo, binarismos, natureza/cultura e a divisão sexual no trabalho desportivo, trazemos algumas descrições, como esta de Kuper, avaliando D’Andrade: “[...] Talvez o parentesco e a divisão do trabalho por sexo tenham algo a ver, afinal de contas, coma biologia da reprodução; ou, como insistia Foucault, o conhecimento deva ser compreendido em relação ao poder; [...]” (Adam Kuper, 2002, p. 311). $\mathrm{Ou}$, também, teria a ver com a tecnologia de gênero, camuflada na lógica naturalizante da biologia? 
Inserindo a lógica biologizante no contexto do dimorfismo, traçamos uma sucinta ideia sobre o isomorfismo na história, conforme descrito por Berenice Bento (2006) em seu estudo intitulado "A reinvenção do corpo", no qual a autora nos dá informações contundentes nas reflexões sobre a origem da "naturalização" dos corpos. Percebe-se a engenharia da construção dos corpos sexuados a partir de uma intencionalidade, onde a autora, citando Laqueur (2001), baseada nas diferenças anatômicas e biológicas, afirma "a inexistência de obras escritas antes do século 17 que tivesse essas diferenças como tema" (p.113).

A autora utiliza estudos de Foucault para esclarecer que, entre os anos de 1860-1870, proliferaram-se discursos médicos com o objetivo de provar a origem da biologia nos corpos sexuados (p.113). Mais adiante, afirma que, no isomorfismo, existia um único corpo. O corpo da mulher era igual ao do homem, sendo a vagina um pênis invertido (p. 115).

Segundo Bento, "para os médicos da Renascença, havia um sexo único e pelo menos dois sexos sociais com direitos e obrigações distintos. $\mathrm{O}$ sexo biológico, que se usa como base e referência para a construção dos gêneros contemporaneamente, inexistia. [...]" (BENTO, 2006, p. 119).

No processo corpo/sexo/gênero, investigando a transexualidade, a autora também mostra comportamentos e hábitos sociais diferentes do sexo apresentado (como vestir-se, proceder), ou seja, sexo feminino com comportamentos considerados na cultura como do sexo oposto e vice versa. Bento também aborda as mudanças de sexo adquiridos cirurgicamente, por desejo, onde discorre sobre os ajustes de comportamentos (por imposição médica/institucional) adequados para o sexo, que será modificado por conta da mudança corporal.A partir disso, podemos interpretar que a autora confirma a existência da tecnologia de gênero como um processo político de manutenção de normas sociais.

Por entendermos que as diferenças não são inatas, buscamos as ideias da criadora da obra referida, que se utiliza de várias autoras, dando respaldo à temática, como Mireya Suárez, que propõe a questão: “[...] por que as mulheres têm um valor inferior, em relação aos homens, em 
todas as sociedades?" (p. 72). E, em menção à Chodorow, citado nos estudos de Ortner, Bento relata:

Ortner constrói uma tipologia comportamental na qual o homem é identificado com oracional, o abstrato, a objetividade (cultura), e a mulher, com a praticidade, a concretude e a subjetividade (natureza), embora ela tenha alertado (em uma linha apenas) que essas diferenças não são inatas ou geneticamente programadas (Ibid., 2006, p. 73).

Nos estudos de Ângela Maria Souza (2002), com o texto intitulado "O viés androcêntrico em biologia", a autora nos mostra o androcentrismo vinculado à ciência moderna. Para quem, assim como o gênero, a ciência é um construto social, ela afirma que "a originalidade da crítica feminista reside na identificação e na denúncia do forte viés androcêntrico que permeia o pensamento científico e os seus desdobramentos [...]" (p. 78).

Quanto ao viés androcêntrico na linguagem e nas representações do mundo nas ciências biológicas, vejamos o que diz a autora:

[...] nos curso de formação de biólogos e, é claro, na mídia pretensamente 'científica': o espermatozoide é o herói da criação. É bastante recente a noção dos dois gametas como parceiros e o reconhecimento da intensa e definitiva participação do óvulo no processo de formação do novo ser: [...] Uma abordagem da Biologia Molecular desprovida do viés masculino permite a constatação de que o óvulo é até mais ativo do que o espermatozoide [...] (Ibid.,2002, p. 81).

Observamos a sutileza da construção das diferenças sexuais a partir de um processo orgânico funcional, culminando com a hegemonia masculina. O simples fato do espermatozoide no comando se desdobra na problemática da submissão feminina, vinculando-se ao androcentrismo no poder.

Numa tentativa de compreender as diferenças sexuais, a começar pela física-fisiológica-corporal, vejamos os resultados apontados por estudiosos do dimorfismo sexual, seja pela perspectiva biológica, comparativa, crítica, narrativa, ou experiência vivida:

Para Beauvoir, "Ninguém nasce mulher: torna-se mulher. Nenhum destino biológico, psíquico, econômico define a forma que a fêmea humana assume no seio da sociedade; [...]" (BEAUVOIR, 1967, p.09). 
Com o método narrativo colocando em evidência a experiência vivida, a autora afirma que: "[...] até os doze anos a menina é tão robusta quanto os irmãos e manifesta as mesmas capacidades intelectuais [...]" (p.09-10).

Guedes, em seus estudos biologizantes com métodos comparativos, descreve:

As diferenças sexuais na massa muscular são mínimas durante a infância, com os meninos apresentando uma ligeira maior proporção de massa muscular em relação ao peso corporal. No entanto, durante e depois da adolescência, as diferenças sexuais se evidenciam de forma bastante acentuada (GUEDES, 2002, p.39-40).

Seguindo a mesma lógica, mas acrescentando um olhar social, Niemam diz o seguinte:

[...] mesmo em termos de atletas de elite, as mulheres, comparadas aos homens, possuem uma menor massa corporal magra, maior porcentagem de gordura corporal, menor força corporal, menor volume sistólico e maior frequiência cardíaca, menor volume sanguíneo e conteúdo de hemoglobina, e menos vo2max (NIEMAN, 1999, p.30).

Esta passagem significa que as mulheres são fisiologicamente menos desenvolvidas que o sexo oposto. Vale frisar que isso não tem a ver com menor saúde. Na sequência, o autor em questão lança uma interrogação: "Por que as atletas de resistência de elite são mais lentas que os atletas masculinos? Será por causa das diferenças biológicas reais ou os números refletem restrições sociais e culturais?" (p.30). Em contrapartida, tentando desvendar o " $\mathrm{X}$ " da questão, nós lançamos a seguinte indagação: as diferenças de que fala o autor não seriam construídas, incorporadas e naturalizadas, ao invés de reais? Porque, para nós, "reais' dá uma ideia de "verdadeiro", e, neste caso, "naturais". O próprio autor responde ambas as questões, quando afirma "[...] entretanto, as mulheres vêm participando de maratonas há apenas 25 anos aproximadamente, enquanto os homens têm tido a oportunidade de praticá-la há quase um século.” ( p.30).

Conforme avaliamos, os autores têm em comum a análise das diferenças dimórficas entre os sexos e nos permitem interpretar os mesmos resultados em seus estudos, ou seja: que, na infância, não há tais diferenças ou são insignificantes, modificando-se na adolescência. 
E quando comparamos as fases anteriores com a adulta, percebemos tais diferenças evidenciadas. Portanto, nos utilizamos de Simone de Beauvoir e Guacira Louro nas passagens que seguem, que vão nos aproximar do "X" da questão:

[...] em verdade, a influência da educação e do ambiente é aqui imensa. [...] Assim, a passividade que caracterizará essencialmente a mulher "feminina" é um traço que se desenvolve nela desde os primeiros anos. Mas é um erro pretender que se trata de um dado biológico: na verdade, é um destino que lhe é imposto por seus educadores e pela sociedade. A imensa possibilidade do menino está em que sua maneira de existir para outrem encoraja-o a por-se para si. Êle faz o aprendizado de sua existência como livre movimento para o mundo; rivaliza-se em rudeza e em independência com os outros meninos, [...] subindo nas árvores [...] êle apreende seu corpo como um meio de dominar a natureza e um instrumento de luta [...] através de jogos, esportes, lutas, desafios, provas, encontra um emprego equilibrado para suas forças; [...]. (BEAUVOIR, 1967, p. 21).

Vejamos o que diz Guacira Louro:

[...] De acordo com as mais diversas imposições culturais, nós os construímos de modo a adequá-los aos critérios estéticos, higiênicos, morais, dos grupos a que pertencemos. As imposições de saúde, vigor, vitalidade, juventude, beleza, força são distintamente significadas, nas mais variadas culturas e são também, nas distintas culturas, diferentemente atribuídas aos corpos de homens ou de mulheres. Através de muitos processos, de cuidados físicos, exercícios, roupas, aromas, adornos, inscrevemos nos corpos marcas de identidades e, conseqüentemente, de diferenciação [...] (LOURO, 2007, p. 15).

Essa análise nos permite dizer que a experiência de vida, os hábitos e comportamentos impostos pelas normas sociais de gênero, bem como a histórica disparidade entre os sexos em inserções desportivas, influenciam no desenvolvimento das diferenças sexuais, dimorfismos e fortalecimentos de binarismos. Conforme percebemos nesta abordagem, é na pré-adolescência que as meninas são veementemente direcionadas a um comportamento rigoroso, pautado na feminilidade, enquanto o menino segue em práticas e inserções socioculturais que evidenciam a força física. Desta forma, “[...] Os corpos são significados pela cultura e são, continuamente, por ela alterados [...]. O corpo se altera com a passagem do tempo, com a doença, com mudanças de hábitos alimentares e de vida [...].” (Ibid., 2007, p.14). 
Contribuindo com a discussão, Priscila Dornelles (2007), com seu estudo focado nas práticas de educação física escolar entre os sexos, permite-nos perceber como a tecnologia de gênero entra no cenário da educação, revelando-nos a influência desta disciplina específica na produção dos corpos generificados.

Essencializar as marcas corporais atribuindo-lhes a
determinação de como viver e ser masculino e feminino é
significar que os destinos de meninos e meninas não são
culturais, sociais e históricos, e sim definições naturais que se
vinculam, em grande parte, aos modos pelos quais a Educação
Física escolar produz corpos generificados. (DORNELLES,
2007, p. 140).

Despertando para o controle das normas sociais vinculadas nas vivências infantis entre os sexos e refletindo sobre o papel social dos brinquedos, onde não há escolhas e autonomia, apenas imposições, vale observar os estudos da antropóloga Suely Messeder, que diz: “[...] A tecnologia de gênero presente nos brinquedos funciona de maneira bastante severa, para as meninas e meninos que não concordam com esta divisão sexual dos brinquedos [...]" (MESSEDER, 2012, p. 98).

Desta forma, a fragilidade física nas mulheres versus força nos homens, enquanto inatas, em virtude das discussões pós-estruturalistas, são socialmente construídas, logo, trata-se de um paradigma supostamente verdadeiro.

Ressaltamos que, segundo os estudos, as discussões de gênero pela via do corpo e sexualidade foram impulsionadas na segunda onda do feminismo, datado da década de 70 , e relacionando as diferenças sexuais como patriarcado, de acordo com estudos, este último fenômeno também foi naturalizado como origem da história. Assim, tanto um quanto o outro necessitam ser desmascarados como falsoideológico, pensados como subsídios nas contribuições para as melhorias nas relações de gênero.

Veremos o que diz Saffioti, ao analisar os estudos de Lerne sobre o patriarcado:

"[...] Neste aspecto, faz fascinante incursão pelas sociedades de caça e coleta [...] revela uma série de exemplos de complementaridade entre as categorias de sexo, assim como o desfrute, por parte das mulheres, de status relativamente alto. [...]". Saffiot revela que, "Talvez esta seja 
a razão pela qual Lerne usa sempre a palavra relativa para se referir à igualdade entre homens e mulheres. [...]" (SAFFIOTI, 2011, p. 119). Nesse estudo, o patriarcado não existe, nem o matriarcado, mas a igualdade na relação.

Observando a autora supracitada, ao se reportar a Johnson, percebemos como se originou o processo "controle ou dominação", iniciando na relação entre humano/natureza, se transformando em humano versus natureza, conforme descreve:

Quando se passou a criar animais para corte ou tração, sua reprodução mostrou-se de grande valor econômico. Foi fácil, então, perceber que, quanto mais filhos um homem tivesse, maior seria o número de braços para cultivar áreas mais extensas de terra, o que permitia maior acumulação [...] Isto tudo foi crucial para estabelecer entre os homens e as mulheres relações de dominação-exploração. (Ibid., 2011, p. 119-120).

Para Saffioti (2011), não se trata de uns serem melhores que outros, mas de disputa pelo poder, sendo o patriarcado um exemplo da transformação do equilíbrio e da relação igual em controle e dominação (p.120).

\section{Novo campo de trabalho, nova identidade de gênero que se desenha}

Diante das diferenças sexuais comportamentais, binarismos e dimorfismos, no esporte, grupos de mulheres se deslocam para fora, desafiando paradigmas naturalizantes, rompendo a lógica da biologia. As mulheres fortes. As mulheres masculinizadas se apresentam.

Nesse assunto, Patrícia Lessa traz à discussão as mulheres nos esportes, citando a inserção destas nas práticas desportivas, antes proibidas por meio de leis; o papel do higienismo nas práticas da educação física desfavorecendo as mulheres; a vigilância sobre o corpo; e, dentre tantas questões, a quebra de tabus, que a autora chama de "drible no mundo". Ao discorrer sobre as resistências e lutas ao longo da história, ela afirma: "A fragilidade física caiu por terra quando a explosão das academias e dos exercícios resistidos (musculação) entrou na ordem do dia [...]" (LESSA, 2005, p.167). 
Há quem se espante ao ver mulheres hipertrofiadas, sobretudo, nos membros superiores ${ }^{4}$, tendo como esporte o fisiculturismo, ou as que correm o mesmo percurso masculino, ficando para trás deste sexo, apenas milésimos de segundos ${ }^{5}$, como, por exemplo, as corredoras de elite. Vale ressaltar como novo campo de trabalho, embora necessite de ampliação, as treinadoras de futebol e as árbitras desta modalidade, que, no desempenho da função, adotam o comportamento adquirido pelo sexo oposto, de autonomia e liderança, controla em campo um quantitativo de aproximadamente 22 homens (número de jogadores correspondente às duas equipes para o confronto), sendo que, as que compõem a última função, ainda julgam e aplicam sanções a estes sujeitos (advertem e expulsam com cartões). Poder?

Relacionamos estas abordagens com a divisão sexual no trabalho desportivo, onde percebemos a ambiguidades da problemática: disparidades na divisão sexual e nas oportunidades, justificadas pelas diferenças físicas e sua continuidade, mesmo quando as mulheres desportistas passaram a apresentar avanços físicos e invejáveis desempenhos motor-físico-corporal, quando deveriam ocorrer reduções nas disparidades sexuais no trabalho.

Conforme Mirla Cisne, citando Lobo (1991), "Analisar, portanto, a divisão sexual do trabalho é indispensável para desvelar o antagonismo de classe [...] Em outros termos, é necessário 'desomogeneizar' a classe trabalhadora, percebendo que ela tem dois sexos [...]" (CISNE, 2012, p.111). Caberia acrescentar: dois sexos e uma política sexista favorecendo apenas um.

Seguindo o entendimento de Lessa, quando expõe que o futebol é ótimo exemplo para empreendermos uma discussão sobre as mulheres nos esportes (LESSA, 2005, p. 166), destacamos a arbitragem neste campo por vermos que continua sendo um setor de resistência à participação feminina, que, por outro lado, adentra ao setor de trabalho formal ${ }^{6}$. Observando o histórico dessa modalidade desportiva, diante das leis e proibições da mulher nos esportes brasileiros, notaremos o que a autora expõe:

\footnotetext{
${ }^{4}$ Tronco: braços, peito, costas.

${ }^{5}$ Ver tempo de atletas corredores de elite

${ }^{6}$ Lei 12.867, sancionada em 10/10/2013, pela então presidenta da República.
} 
[...] em 1941[...] o Conselho Nacional de Desportos (CND) criou o Decreto Lei 3.199, que no artigo ${ }^{\circ} 54$ dizia que, as mulheres não poderiam praticar esportes 'Incompatíveis com sua natureza'. Em 1965 com a deliberação $\mathrm{n}^{\circ} 7$ definiram-se regras para a participação das mulheres nos esportes, não sendo permitida às mulheres a pratica do futebol [...] E somente em 1979, com a deliberação $\mathrm{n}^{\circ} 10$, a anterior é revogada [...] (Ibid, 2005, p. 165).

Sobre o papel do futebol, influenciando na tecnologia de gênero, vejamos outras fontes:

[...] O futebol, esporte violento, tornaria o homem viril e, se fosse praticado pela mulher, poderia masculinizá-la, além da possibilidade de lhe provocar lesões, especialmente nos órgãos reprodutores. [...] nas últimas décadas, presenciamos algumas mudanças [...] o futebol passa a ser praticado por mulheres [...]. Essa participação das mulheres foi autorizada pelo Conselho Nacional de Desporto (Brasil 1979, Brasil 1983) [...] (EUSTÁQUIA; ALTMANN, 1999, p. 58).

Segundo Reis e Arruda (2011), nota-se um crescimento da presença da mulher no meio futebolístico nas últimas duas décadas, quer seja como jogadoras, quer seja como treinadoras, árbitras e bandeirinhas. Embora exista uma busca cada vez mais significativa de mulheres neste campo, como exemplo, citamos o curso de arbitragem da Federação Paulista de Futebol, no qual, constataram os autores, poucas conseguem atingir a categoria A "ouro" de árbitros da Federação. Sobre esta categoria, entende-se ser o ápice desta profissão.

A priori, podemos compreender que o obstáculo maior para as mulheres se inserirem no esporte empreendedor, considerado setor masculinizado, seguia a mesma lógica de todos os outros setores: as diferenças sexuais consideradas biológicas/inatas, binarizando os papéis sociais, fortalecidas pela eugenia, amarrada na lei, cujas práticas desportivas eram de exclusividades masculinas. Com a revogação das leis, passou-se a centrar exclusivamente no poder.

Ao longo dos anos, livres para as participações desportivas, muitas mulheres avançaram fisicamente. Assim sendo, neste século, no Brasil, o futebol é um novo campo empreendedor para as mulheres, ocorrendo a inserção feminina na função da arbitragem. Aliando a competência física ${ }^{7}$ com a técnica, as mulheres mostraram capacidade para exercer

${ }^{7}$ Comprovando aptidão física, em provas físicas, de índices para as mulheres (consideradas legais). 
o posto, mas não é comum vermos a presença feminina na mesma medida quantitativa e nos mesmos espaços que vemos o sexo oposto, como, por exemplo, em mega eventos como a Copa das Confederações e a Copa do Mundo. Inquieta-nos saber: são eventos exclusivamente masculinos? Assim, não só persiste a divisão sexual para o trabalho no setor do futebol, como a exclusão. Neste caso, extinguiu-se a lei, não o poder.

\section{Novo episódio de gênero no campo do futebol e um moderno dispositivo de exclusão}

Nos últimos anos, no Brasil, para a mulher que deseja se tornar árbitra de futebol e participar das competições masculinas profissionais, deve seguir as mudanças ocorridas nos critérios físicos: a igualdade física entre os sexos, atestada em avaliações físicas de índices masculinos. Vejamos o documento:

Ofício Circular n ${ }^{\circ}$ 033/CA-CBF/08, da Confederação Brasileira de Futebol - $\mathrm{CBF}^{8}$, item 6.1: "em consonância com a circular 1104/FIFA/15.08.07, a árbitra e a árbitra assistente, para atuar em competições masculinas deverão alcançar os índices estabelecidos, respectivamente, para o quadro masculino", (trata-se de índices físicos). Seria a prova do sexo?

Deste modo, analisando os documentos concernentes à arbitragem em futebol e notícias online, observamos que, no período do episódio em discussão, ocorreu a formação de dois grupos de árbitras: as mulheres fisicamente aprovadas no masculino (árbitras do grupo masculino), podendo atuar em diversas competições deste sexo (com algumas exceções de eventos não revelados nos documentos), e as reprovadas nesta prova, porém, aprovadas em índices físicos femininos (grupo denominado RENAF - feminina), podendo atuar em competições exclusivamente do mesmo sexo ${ }^{9}$.

${ }^{8}$ Fonte online: www.cbf.com.br/arbitragem/informações

${ }^{9}$ Nesse período, no Brasil, não havia competição feminina a nível nacional.Há anos não ocorria o campeonato brasileiro feminino. No mesmo ano do Ofício Circular da FIFA, implantou-se a Copa do Brasil Feminino, ocorrendo a seleção de mulheres para ampliação de gênero, mobilizando todas as federações do País, tendo a CBF 
Avaliando os novos modelos de avaliações físicas, através de estudos, notamos que as provas físicas anteriores, eram diferenciadas por sexo. $\mathrm{Na}$ base documental, detectamos nos testes físicos femininos aprovações significativas no quantitativo das mulheres, por isso, consideramos tais provas diferenciadas, como proporcional ao sexo, devido ao fenômeno histórico causado pela tecnologia de gênero.

Trazendo uma ressalva, após a outorga do ofício, a Confederação Brasileira de Futebol e algumas Federações prosseguiram incluindo nas competições profissionais masculinas as árbitras não aprovadas no atual modelo. Até aproximadamente o ano de 2010, elas foram escaladas nessas categorias de jogos, inclusive em grandes confrontos, como os clássicos.

A fim de situar a leitora (o), na Bahia, em janeiro de 2007 (meses antes da implantação das novas normas de arbitragem) pela primeira vez, uma árbitra (baiana) apitou jogo na principal competição masculina do estado, confronto entre Vitória X Poções. Antes a este marco histórico, neste território, as ínfimas oportunidades ocorridas eram desenvolvidas na função de auxiliar (bandeirinha). Lembrando que, até este período, as provas físicas eram separadas por sexo e tinham outro padrão.

Sobre o fator avaliações, Cerqueira et al. (2011), no texto intitulado "Análise do modelo de avaliação física aplicado aos árbitros de futebol pela FIFA", criticando o atual modelo de provas físicas na arbitragem, corroboram com nossas buscas e nos informam que a FIFA tem imprimido mudanças significativas nas baterias de testes para a avaliação funcional do árbitro.Contudo, segundo os mesmos, tais mudanças não atendem às exigências requeridas, uma vez que "uma avaliação física deve simular ao máximo a situação real da atividade a ser avaliada [...]" (p.426). Os autores também demonstram que estes testes apresentam diferentes padrões de exigência física, de acordo com a divisão sexual.

Quando os mencionados interpretam os padrões de avaliações físicas em questão e relacionam à categoria de gênero, concluem que as mulheres possuem vantagens ao se submeterem aos testes. Por isso, concordaram quando a $\mathrm{CBF}$, seguindo o modelo da FIFA, determinou que as mulheres que quiserem arbitrar jogos masculinos de nível 
nacional ou internacional devem apresentar os índices dos homens nos testes físicos (Ofício Circular n 44/2007-CA/CBF).

Quando os mesmos criticam as provas físicas realizadas diferentemente entre os sexos e afirmam que: “[...] Estas diferenças estariam justificadas se as árbitras estivessem limitadas a dirigir partidas de futebol feminino [...]"10 (Ibid., 2011, p.428), parece piada, já que só havia uma competição do sexo, e também, quando não se posicionam sobre a pauta entre os critérios da $\mathrm{CBF}$, que reitera a participação do sexo masculino nas competições femininas, fica nítido que a questão é descentrada da crítica do modelo de prova física e centrada na disputa do campo.

Desta forma, os autores supracitados nos ajudam a compreender como estas instituições aderiram efetivamente aos novos padrões físicos. Seriam as supostas vantagens físicas de gênero, das quais tratam os autores, questionadas pelas falsas ideias de "requerer a igualdade de gênero" através do fisiológico e da força física entre os sexos? Interessa-nos refletir por que quando as mulheres se colocam socialmente iguais aos homens em postos a eles historicamente beneficiados, uma parte da sociedade se move contra.

Contudo, por um lado, estamos de acordo com a posição dos autores no que diz respeito ao modelo atual de avaliação física dos árbitros, que não se mostra adequado para medir o que se propõe. Além de não avaliarem a capacidade aeróbica, que é uma importante variável fisiológica para o árbitro, o teste de corrida de $150 \mathrm{~m}^{11}$ não é compatível com os estímulos de alta intensidade aos quais os árbitros são submetidos, que normalmente não ultrapassam corridas de $30 \mathrm{~m}$. (Ibid., 2011, p.429). Por outro lado, discordamos dos autores supracitados, pois, seja qual for o modelo físico adotado pelas instituições desportivas, defendemos que ocorra com índices físicos diferenciados entre os sexos, atestando a aptidão física das mulheres.

\footnotetext{
${ }^{10}$ Fundamentadas no site da $\mathrm{CBF}$, atualmente existem duas competições femininas nacionais: a Copa do Brasil e o Campeonato brasileiro, contra uma vasta lista de competições masculinas. E, no período dos estudos dos autores em questão, só havia uma competição feminina, a primeira citada. A segunda, de acordo com os dados encontrados, foi reincorporada em 2013.

${ }^{11}$ Segundo as fontes analisadas, são $150 \mathrm{~m}$ percorridos de 20 a 24 vezes, em 30segundos, com intervalos que variam de acordo com a função: 40s (árbitro (a) assistente) e 45s. (árbitro (a) central). Além de outra prova - percorrendo por 6 vezes $50 \mathrm{~m}$, em tempo de 6 a 6.4 segundos, com intervalo de 1,30s (uma após a outra).
} 
Assim, divergimos quando eles não desejam considerar a tecnologia de gênero nos testes para os árbitros e as árbitras.

Segundo interpretamos na Relação Nacional dos árbitros de futebol (2011 a 2014) e as Normas para Classificação - na Relação Nacional dos árbitros (2011/2012), até 2012, havia em média, 80 mulheres no total de árbitras da CBF, reduzindo em aproximadamente 64 na atualidade, contra mais de 400 do sexo oposto ${ }^{12}$. Analisamos que são várias as categorias de árbitros e vimos que há um limite de vagas para o quando nacional ( $\mathrm{CBF}$ ), pautadas às que lograrem êxito na prova do sexo: na categoria CBF1 (a principal de caráter nacional) "[...] será composta por [...] até 08 (oito) árbitras e 16 (dezesseis) árbitras assistentes [...]" (Normas para classificação, 2011, p, 53), enquanto que ao masculino somam-se cento e dez para esta categoria.

Nessa trajetória, no enfrentamento às disputas de força física entre os sexos, mesmo à base de grandes obstáculos, como a prova do sexo, algumas mulheres árbitras lograram êxito no requisito físico dentro do modelo supracitado gradativamente (do quantitativo total, uma média de 20 estão aptas), desestabilizando a lógica naturalizante. Porém, mesmo estas estando em pé de igualdade física com os homens, não estão em todos os eventos, como o recentemente ocorrido no Brasil: a Copa do Mundo. Seria o episódio da igualdade física, um novo dispositivo de exclusão?

Aqui, a igualdade social de gênero está arrolada a corpo/ sexo e poder. Diante disto, como pensar na equidade social e de gênero a partir da igualdade física entre os sexos?Onde está o problema da divisão sexual no trabalho desportivo? Qual o "X" da questão? São as diferenças físicas entre os sexos?

Nossas análises nos permitem responder: Não, o poder. Não necessariamente disputa de poder, mas o poder localizado no sujeito e a estratégia de perpetuação de hegemonia.Temos que considerar que os "corpos culturais" são constantemente orquestrados em sua construção pela tecnologia de gênero e, como sugere Lauretis (1998), a ideologia de gênero é fabricada pelos aparelhos institucionais em nosso cotidiano.

${ }^{12}$ Contagem nossa baseada na fonte - considerando a margem de erro. 


\section{A categoria "gênero" operada nas análises sobre "mulheres e arbitragens"}

Para Lauretis (1998), no texto intitulado "Tecnologia de gênero", o conceito de gênero como diferença sexual é a diferença entre a mulher e o homem, o masculino e o feminino, arrolado no sexual. Segundo a autora, a escrita feminina, a feminilidade, as diferenças físicas, biológicas e tantos outros fatores são derivados, a partir da ênfase no sexual. "Isto é, conceito limitado". Trazendo uma reflexão sobre a questão de gênero dentro destes derivados, Lauretis afirma que "o pensamento feminista permanecerá amarrado aos termos do próprio patriarcado ocidental, [...] e assim tenderá a reproduzir-se, retextualizar-se [...]" (p.207).

Por outro lado, a autora ressalta a importância do conceito de gênero dentro do contexto que critica, justificando o fato de ter servido de base e sustentação para as intervenções feministas, mas sugerindo a elaboração de um conceito que não esteja tão preso à diferença sexual. Ela pensa o gênero a partir de uma visão foucaultiana, que vê a sexualidade como uma "tecnologia sexual". Para a autora, gênero, como representação e auto representação, é produto de diferentes tecnologias sociais. Utilizando Foucault, afirma que gênero é "o conjunto de efeitos produzidos em corpos, comportamentos e relações sociais [...]" (Ibid., 1998, p.208).

Ao mesmo tempo em que a autora apresenta no texto as limitações do conceito de gênero como diferença sexual, admite que nós, pesquisadores feministas, devemos estar cientes de que poderemos ser, em certos momentos, cúmplices desta limitação. Tal cumplicidade se revela pela dinâmica da diferença sexual ser uma representação de gênero, cujo conteúdo rebate diretamente na vivência das pessoas. Com efeito, construímo-nos como corpos sexuados, definidos como homens e mulheres. Desta forma, acolhemos a seguinte citação: "Os homens e as mulheres não só se posicionam diferentemente nessas relações, mas - e esse é um ponto importante - as mulheres são diferentemente afetadas nos diferentes conjuntos." (p. 215). Muito embora sejamos conscientes das múltiplas diferenças que estruturam as relações de gênero, tais como: raça, classe, geração, regionalidades, territórios, nações.

Conscientes da limitação de gênero, focados nas diferenças sexuais, 
biológicas e dimórficas, cremos que esta discussão ainda não pode ser finalizada, nem prescindida, devido a tais fatores serem o liame da cultura sexista que perpetua a divisão sexual no trabalho desportivo, nas atividades de comando, consideradas "trabalho masculinizado", mais especificamente a arbitragem em futebol. Nesta função, cremos que, diante dos progressos em gênero, em termos de melhorias na igualdade social, e dos avanços culturais, o corpo, a biologia, a fisiologia e os dimorfismos sexuais têm sido recorridos, em detrimento das mulheres, quando entra em cena a tecnologia de gênero, em prol de conservar a hegemonia masculina no campo.

Diante do contexto, adotamos como conceito de gênero a construção social e política numa cultura, referenciada no sexual, como na visão de Scott (1995), para quem gênero "[...] é um elemento constitutivo de relações sociais fundadas sobre as diferenças percebidas entre os sexos [...]” (p.89).

A ampliação destas questões nos permitiria avançar para outros olhares, como a hipótese que desenhamos propor (para estudos futuros): diante da violência de gênero, seriam as mulheres fisicamente mais fortes, com maior probabilidade de escapar das possíveis violências físicas, sobretudo no setor doméstico e familiar ${ }^{13}$ ? Seria a autodefesa física/corporal mais uma forma de proteção, além da proteção pública? A porrada dada, ninguém tira!

\section{Considerações finais}

Nesse estudo, discutimos as diferenças físico-corporais e fisiológicas entre os sexos, relacionando com o progresso cultural e dialogando com a tecnologia de gênero, fenômeno que beneficiou o sexo masculino em detrimento do oposto, tanto na esfera física quanto social. Fator que, sob a influência cultural e da educação, desencadeou o desenvolvimento da hegemonia masculina e o androcentrismo nos esportes.

\footnotetext{
${ }^{13}$ Não se trata de crianças - embora nesta fase as meninas devam ser iniciadas com seriedade nas práticas físicas, esportes, lutas e jogos, nas aulas de educação física e lazer.
} 
Mostramos um novo campo de trabalho masculinizado com inserção feminina: o futebol empreendedor, e ao mesmo tempo, vinculado a um "jogo" de poder nos esportes, com dispositivos de controle e exclusão de gênero, tendo como "pontapé inicial" as leis proibitivas baseadas no fisiológico/biológico sexual, suposto natural. Com as respectivas leis postas em "escanteio" (revogadas), "reinicia-se" o jogo.

Contudo, diante das discussões do corpo socialmente construído, o jogo ganha nova forma: as estratégias de controle do campo, com a prova do sexo, moderno dispositivo de exclusão, com o qual as mulheres, para exercerem a função de árbitras em competições profissionais masculinas, devem ter o mesmo condicionamento físico que o sexo masculino de mesma função. Igualdade física é sinônimo de igualdade social de gênero? Ocorre que nas oportunidades, as deliberações institucionais indicam quantitativos sexuais diferenciados para o campo. Como vimos, para os homens, o quantitativo determinado é exacerbadamente maior.

Buscamos refletir sobre uma nova identidade de gênero que se desenha na sociedade. As mulheres fortes. Mulheres masculinizadas. Com a chegada das mulheres nos esportes, temos exemplos que desestabilizam o fenômeno biológico/natural. Nesse sentido, as diferenças sexuais, mais precisamente físico-fisiológica-corporal, sob o paradigma biológico/natural, conforme discutidas aqui, necessitam de continuação nas discussões, perpassando os encontros feministas, adentrando aos encontros de âmbito educacional e instituições outras, como as desportivas, com objetivo de romper o paradigma da fragilidade física versus força inata entre os sexos, e quebrando os padrões hierárquicos de sexo/gênero, visando, principalmente, reduzir as disparidades de gênero no mercado de trabalho desportivo.

Além disso, é preciso compreender o fenômeno das construções sociais dos corpos, enviesadas nas noções de natureza/cultura, isto é, a tecnologia de gênero. Aqui, levamos a cabo os dispositivos de limitação/exclusão de gênero na formação dos corpos sexuados: no aparelho institucional escolar, com os estudos que passeiam pela fabricação de corpos na Educação Física, brinquedos e brincadeiras,as leis e proibições nos esportes e o período da inserção feminina nos esportes. 
Considerando a influência cultural na construção dos corpos sexuados, compreendemos que as oportunidades e inclusões femininas que vêm ocorrendo em práticas desportivas e em setores masculinizados têm possibilitado, na atualidade, a existência de mulheres com o desenvolvimento físico-corporal e aptidões físicas próximas do sexo oposto, que desempenham mesma atividade e, por vezes, superior aos homens que não treinam. Esta questão específica, no entanto, não faz parte da realidade da população feminina, parece uma nova identidade de gênero que se apresenta. Nova cultura?

\section{Referências}

BEAUVOIR, Simone de. O Segundo Sexo Il. Experiência vivida. Trad. Sergio Milliet. São Paulo: difusão Européia do Livro, 1967.

BENTO, Berenice. A reinvenção do corpo: sexualidade e gênero na experiência transexual. Rio de Janeiro: Garamond, 2006.

CERQUEIRA, S.; DA SILVA, I.; MARINS, B. Análise do modelo de avaliação física aplicado aos árbitros de futebol pela FIFA. Revista Brasileira de Medicina do Esporte v. 17 n. 06, São Paulo. /Dec.2011.

CISNE, Mirla. Gênero, divisão sexual do trabalho e serviço social. São Paulo: Outras expressões, 2012.

DORNELLES, Priscila Gomes. Distintos destinos? A separação entre meninos e meninas na Educação Física Escolar na perspectiva de Gênero. Porto Alegre: UFRGS, 2007. 156f. Dissertação (Mestrado em Educação) - Programa de Pós-Graduação em Educação, Faculdade de Educação, Universidade Federal do Rio Grande do Sul, Porto Alegre, 2007.

GUEDES, D. P; GUEDES, Joana. E.R.P. Crescimento, Composição Corporal e Desempenho Motor de crianças e adolescentes. São Paulo: CLR Balieiro, 2002.

Informações de Arbitragem http://www.cbf.com.br/arbitragem/informações 
KUPER, Adam. Cultura: a visão dos antropólogos. Tradução Mirtes Frange de Oliveira Pinheiros. São Paulo: EDUSC, 2002.

LAURETIS, Teresa de. A tecnologia do gênero. In: HOLANDA, Heloísa Buarque de. Tendências e impasses. Rio de Janeiro: Rocco, 1998.

LESSA, Patricia. Mulheres à venda. Londrina: Eduel, 2005.

Mulheres, corpo e esportes em uma perspectiva feminista. Revista Motrivivência, Florianópolis: UFSC, ano XVII, n. 24, p, 157172, junho, 2005.

LOURO, Guacira. O corpo educado - pedagogias da sexualidade: tradução Tomaz Tadeu da Silva. $2^{\mathrm{a}}$ ed. Belo Horizonte: Autêntica, 2007.

MALINOWSKI, Bronislaw. Uma teoria científica da cultura. 3. ed. Rio de Janeiro: Zahar editores, 1975.

MESSEDER, S. A. Precisa isso?!: Desconstruindo o fio das masculinidades nas vivencias de mulheres masculinizadas na escola e no mundo do trabalho. In: Tereza Rodrigues vieira (org.). Minorias sexuais direitos e preconceitos. Brasília: Consulex, 2012, v.01.

NIEMAN, D.C. Exercício e Saúde: Como se prevenir de doenças usando o exercício como seu medicamento. São Paulo: Manole, 1999.

NORMAS para classificação dos integrantes da RENAF. Relação nacional dos árbitros 2011/2012. P.51-54: (01/0511 a 30/04/12). Disponível em: http//www.cbf.com.br/ 201211/

Provas físicas da FIFA para árbitros e árbitros assistentes. Basil, 2007 (on-line). http://www.def.ufms.br/def/cbf/imagem/provafifa.pdf

REIS, P.G.: ARRUDA, A. Mulher, futebol e arbitragem: um espaço de conquista, tensão e resistência. EFDportes. Com, Revista Digital. Buenos Aires, año 16, $\mathrm{n}^{\mathrm{o}}$ 162, Noviembre de 2011. http://www.efdeportes.com/

SAFFIOTI, Helieth. Gênero, patriarcado, violência. $2^{a}$ reimpressão., São Paulo: Perseu Abramo, 2011. 
SCOTT, Joan. "Gênero: Uma categoria útil de análise histórica". Educação e Realidade, v. 20, nº 2. Porto Alegre, jul./ dez. 1995, pp. 71-99.

SOUSA, Eustáquia Salvadora de; ALTMANN, Helena. Meninos e meninas: Expectativas corporais e implicações na educação física escolar. Cadernos Cedes, ano XIX, nº 48, p 52-68, agosto, 1999.

SOUZA, Ângela Maria Freire de Lima. O viés androcêntrico em Biologia. In: Alcântara, Ana Alice e Sandenberg Maria Cecilia (org). Feminismo, Ciência e Tecnologia. Coleção Bahianas - vol. 8. UFBA, 2002. 